NASA Technical Memorandum 107059

\title{
Automatic Radiated Susceptibility Test System for Payload Equipment
}

Hoai T. Ngo

Lewis Research Center

Cleveland, Ohio

John C. Sturman

Analex Corporation

Brook Park, Ohio

Noel B. Sargent

Lewis Research Center

Cleveland, Ohio

Prepared for the

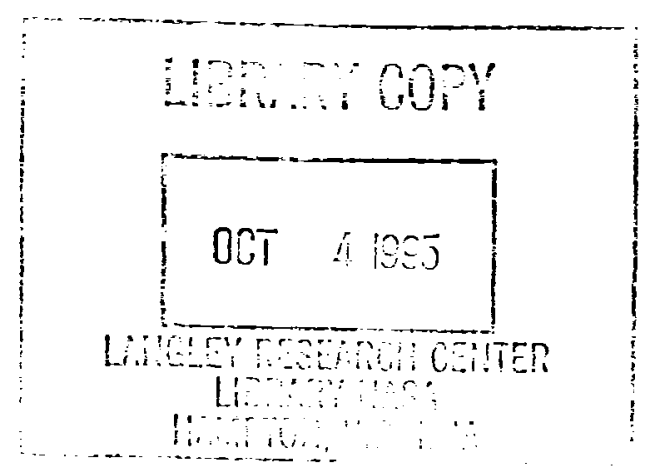

1995 Space Programs and Technologies Conference

sponsored by the American Institute of Aeronautics and Astronautics

Huntsville, Alabama, September 26-28, 1995

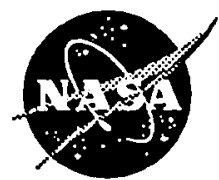

National Aeronautics and

Space Administration 


\title{
AUTOMATIC RADIATED SUSCEPTIBLITY TEST SYSTEM FOR PAYLOAD EQUIPMENT
}

\author{
Hoai T. Ngo \\ National Aeronautics and Space Administration \\ Lewis Research Center \\ Cleveland, $\mathrm{OH} 44135$ \\ John C. Sturman \\ Analex Corporation \\ Brook Park, OH 44142 \\ Noel B. Sargent \\ National Aeronautics and Space Administration \\ Lewis Research Center \\ Cleveland, $\mathrm{OH} 44135$
}

\begin{abstract}
An automatic radiated susceptibility test system (ARSTS) was developed for NASA Lewis Research Center's Electromagnetic Interference laboratory. According to MSFC-SPEC 521B, any electrical or electronic equipment that will be transported by the spacelab and space shuttle must be tested for susceptibility to electromagnetic interference. This state-of-the-art automatic test system performs necessary calculations; analyzes, processes, and records a great quantity of measured data; and monitors the equipment being tested in real-time and with minimal user intervention. ARSTS reduces costly test time, increases test accuracy, and provides reliable test results.
\end{abstract}

\section{Introduction}

Radiated susceptibility testing determines the susceptibility of shuttle payload equipment to radiated electromagnetic fields. This test, which is typically done by the engineer monitoring the equipment, requires a pass/fail condition to be determined at each electromagnetic frequency over a wide test range. The resulting large amount of data is difficult to analyze and manipulate during testing and even after. The automatic test system resolves these difficulties by controlling radiofrequency (RF) equipment, monitoring the equipment being tested, and collecting data. Depending on the equipment's position in the orbiter payload bay, ARSTS can enable the test engineer to readily select a field level or to make modifications for a particular application (such as changing the field intensity to be applied to the equipment under test (EUT) if a susceptibility is detected). With this software, the test engineer can view information in real time-including process time, current

This paper is declared a work of the U.S. Government and is not subject to copyright protection in the United States. test frequency, field sensor readings, and instrument status. It also enables the test engineer to display and print all test setup parameters, test results, and documentation.

For the tests required by MSFC-SPEC 521B, which covers the frequency range of $14 \mathrm{kHz}$ to $18 \mathrm{GHz}$, the field strength must be measured at 1422 frequencies in 1 -percent increments. The amount of time at each frequency depends on the EUT. If the dwell time is $20 \mathrm{sec}$ at each frequency, the test will take over $8 \mathrm{hr}$, not including the time for setup, data acquisition cycle, processing, and display. If failures occur, the test time becomes even longer. Automatically controlling the processes of setting frequencies, tuning signal generator knobs, and adjusting amplifier power can reduce test time.

\section{Overall View}

The ARSTS software automatically executes the test procedure and data recording. This automatic process can be broken into the following steps:

- Data acquisition

- Test instrumentation selection

- Automatic radiated susceptibility process

- User involvement

\section{Data Acquisition}

ARSTS uses power amplifiers, frequency generators, transmitting antennas, modulators, RF switches, and field sensors that are connected by fiber-optic cables to a field meter. The computer controls the interface with the $\mathrm{RF}$ equipment and instrumentation via a general purpose interface bus (GPIB), as illustrated in Fig. 1. This 


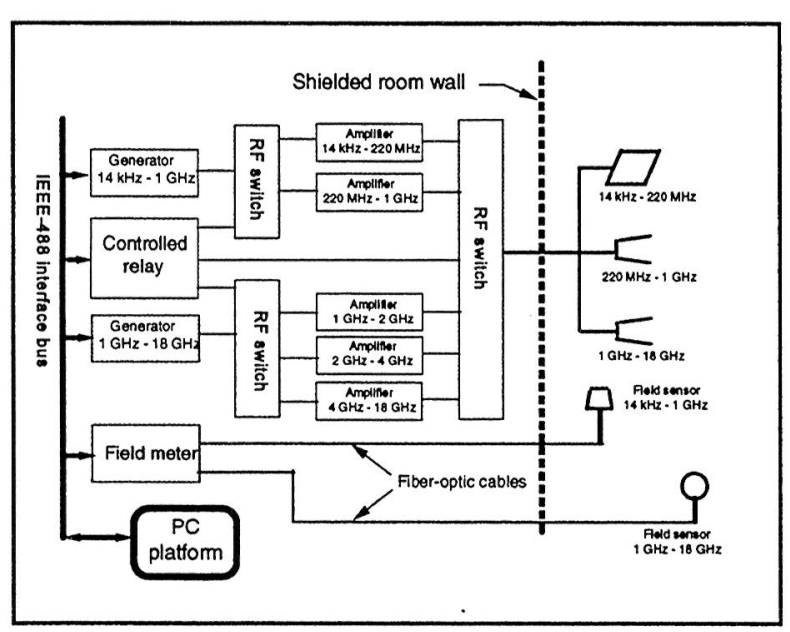

Figure 1.-Automatic system integration.

software enables ARSTS to operate the instruments and to completely control hardware interfaces. ARSTS provides closed-loop, computer-controlled leveling of the field intensity by comparing the output of the radiating system with the radiated level measured by the field sensor in the shield room.

The software is divided into three subsystems:

(1) Display-The display subsystem sets the setup parameters of a susceptibility test, including the test instrument configuration (Fig. 2).

(2) Critical test information-During the tests, this subsystem automatically levels and controls the RF field in real time (Fig. 3).

(3) Data-The data subsystem enables the test engineer to display and print all test results and documentation after a test is complete.

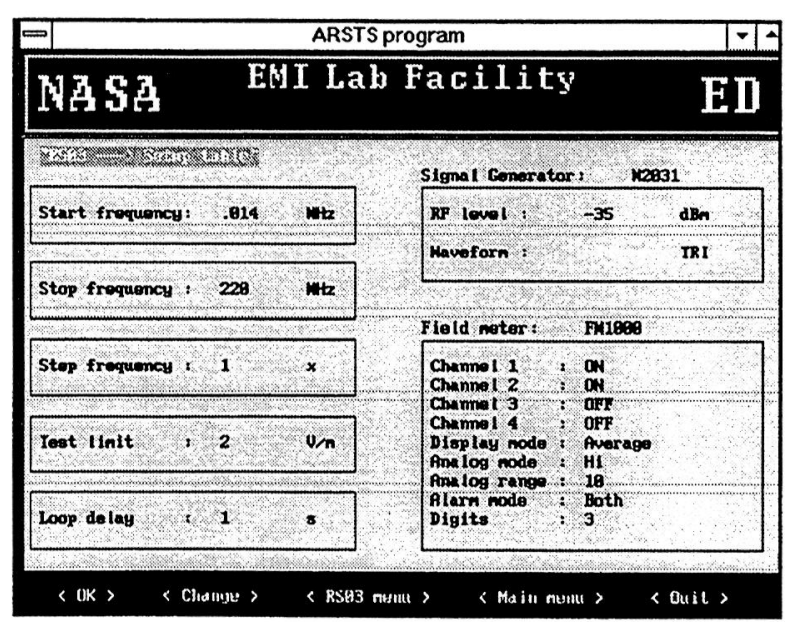

Figure 2.- Test setup screen.

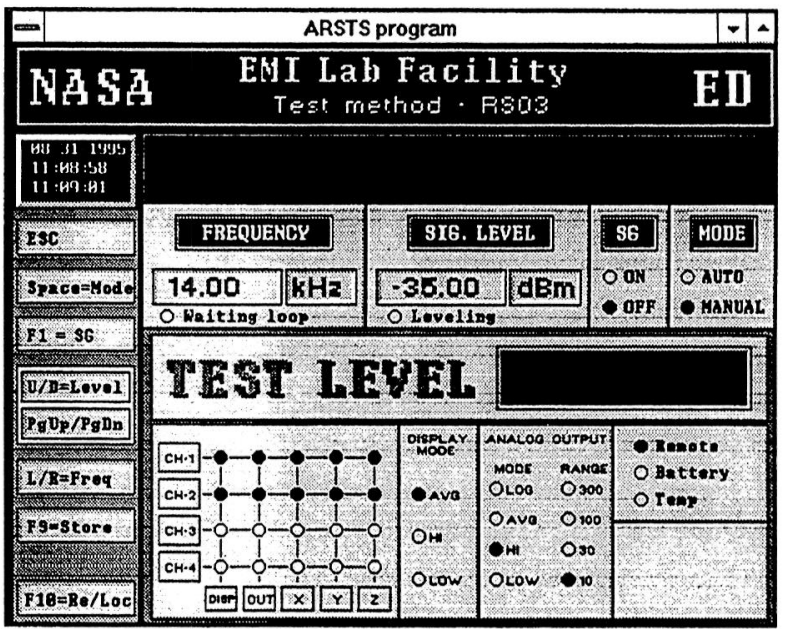

Figure 3.-Susceptibility test monitoring.

\section{Test Instrumentation Selection}

Several things must be considered when choosing the right test instruments to include in the automatic test system:

(1) The system's architecture must be designed with connecting instrumentation to reduce instrumentation costs and software development time. For example, instead of controlling just one amplifier, an RF actuator relay could control a number of amplifiers.

(2) The equipment must be able to operate under the conditions required by the test, such as particular field levels and frequency ranges.

(3) Instruments should come with a standardized, controllable GPIB.

(4) Instruments must be accurate and stable, controlling most functions needed to perform the test.

\section{Automatic Radiated Susceptibility Process}

A closed-loop, automatically controlled, susceptibility process includes several steps (Fig. 4):

(1) The system initializes the hardware by issuing an "off" command to the RF output of the signal generator, then setting a low initial RF level to avoid overstressing the EUT.

(2) Once the test setup has been corrected, the test engineer switches the system to auto mode.

(3) Then, the system decreases or increases the RF level of the signal generator from the equation: 


$$
R F_{\text {new }}=R F_{\text {old }}-20 \log \frac{\text { Field }_{\text {measured }}}{\text { Field }_{\text {desired }}}
$$

The new RF level increases if the measured field is less than the desired field, and it decreases if the measured field is greater than the desired field. The process continues until the measured field approaches the desired field. At this point, the system automatically records the frequency, RF signal level, and threshold level. Then, it continues with the test procedure by stepping-up to the next frequency using a step size predefined by the test engineer or another person responsible for the EUT. The test engineer can measure the EUT's performance throughout its exposure to the electromagnetic field. When a failure occurs, the test engineer determines the susceptible threshold level manually by using the up and down arrow keys on the computer to reduce the RF signal level until the malfunction or degradation completely disappears. The system then records the frequency, RF signal level, and threshold level, as well as a description of the failure.

ARSTS can be used in two interchangeable modesauto and manual. During the auto mode, the test engineer can pause the system by switching it to manual mode

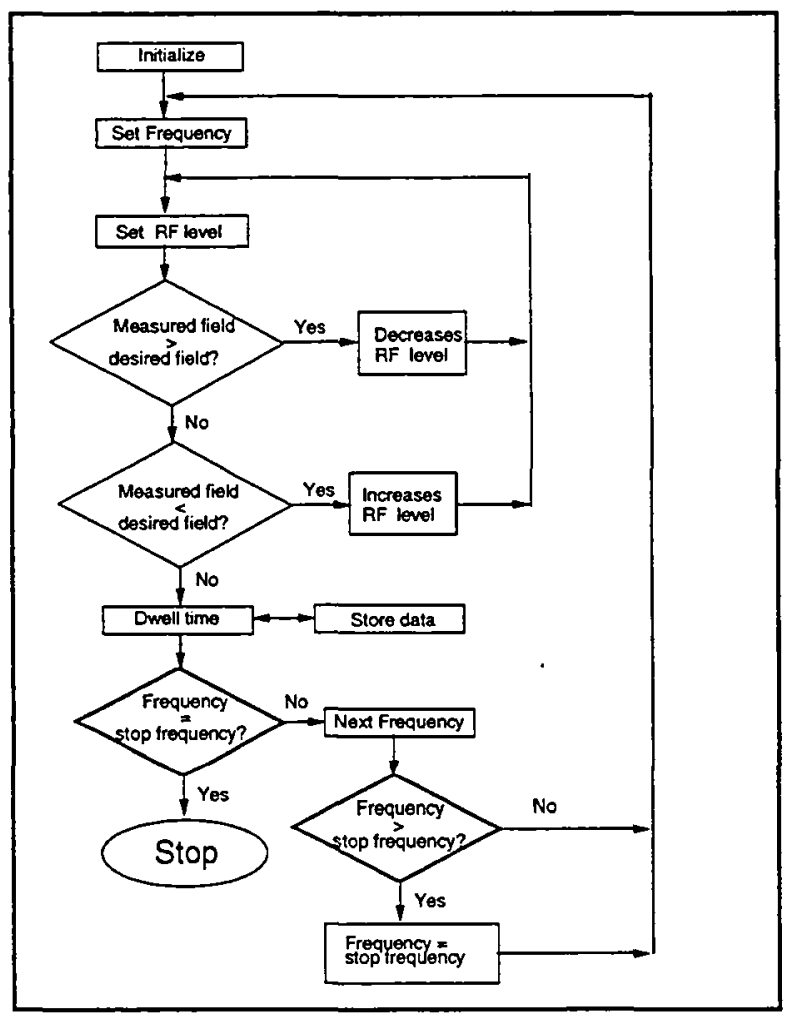

Figure 4.-Automatic process for determining susceptibility. or can turn off the RF generator-this automatically switches the system to manual mode. If the RF signal is turned off, it must be turned back on before the system can be switched to auto mode again.

\section{User Involvement}

While operating ARSTS, the test engineer must enter choices from the menus and input answers to questions about the EUT. In addition, this engineer usually investigates the test setup and sets test parameters such as frequency range, step size, required test level, dwell time, and instrument settings.

Before starting the test, the test engineer places the EUT and field sensors inside the shielded enclosure and positions the antennas $1 \mathrm{~m}$ from the EUT. When the software indicates that the antenna needs to be changed, the engineer manually changes the antenna (the three antennas used respond to different frequency ranges). At this point, the software automatically disables the $R F$ output to prevent any damage to the EUT and to protect personnel from $R F$ exposure. After the antenna is changed, testing can resume.

To make necessary interventions, the test engineer must observe the EUT while it is exposed to the field. This can be done by watching the monitor as it displays images grabbed and stored by the internal software or by another method of observing the test sample.

\section{Concluding Remarks}

The automatic radiated susceptibility test system (ARSTS) benefits electromagnetic interference susceptibility testing of complex space experiments by quickly obtaining, recording, and processing the large amount of data required by MSFC-SPEC-521B. After the test is complete, the test engineer selects a menu option to obtain document-ready test results, including a description of the test items, project titles, operator name, date and time, frequency ranges determined by antenna type, pass or fail marks, and tabulated test results. All results can be saved to disks for future reference.

NASA Lewis is currently adding a 32- by $24-$ by 16-ft shielded enclosure to accommodate larger payloads and a 16 - by 10 - by 8 -ft shielded enclosure to isolate ground support equipment and instrumentation from the Electromagnetic Interference laboratory facility. ARSTS and the new test area will increase NASA Lewis' ability to conduct tests according to military and commercial specifications. 
Public reporting burden for this colvection of information is estimated to average 1 hour per response, including the time for reviewing instructions, searching existing data sources, gathering and maintaining the data needed, and completing and reviewing the collection of information. Send comments regarding this burden estimate or any other aspect of this collection of information, including suggestions for reducing this burden, to Washington Headquaners Services, Directorate for Intormation Operations and Reports. 1215 Jeflerson Davis Highway, Sulte 1204, Arlington, VA 22202-4302, and to the Office of Managernent and Budget, Paperwork Reduction Project (0704-0188), Washington, DC 20503.

\begin{tabular}{|l|l|l|}
\hline 1. AGENCY USE ONLY (Leave blank) & $\begin{array}{r}\text { 2. REPORT DATE } \\
\text { September } 1995\end{array}$ & $\begin{array}{r}\text { 3. REPORT TYPE AND DATES COVERED } \\
\text { Technical Memorandum }\end{array}$ \\
\hline
\end{tabular}

4. TITLE AND SUBTIILE

5. FUNDING NUMBERS

Automatic Radiated Susceptibility Test System for Payload Equipment

6. AUTHOR(S)

WU-963-80-0D

Hoai T. Ngo, John C. Sturman, and Noel B. Sargent

\section{PERFORMING ORGANIZATION NAME(S) AND ADDRESS(ES)}

National Aeronautics and Space Administration

Lewis Research Center

Cleveland, Ohio 44135-3191

9. SPONSORINGMONTTORING AGENCY NAME(S) AND ADDRESS(ES)

National Aeronautics and Space Administration

Washington, D.C. 20546-0001
8. PERFORMING ORGANIZATION REPORT NUMBER

E-9914
10. SPONSORING/MONITORING AGENCY REPORT NUMBER

NASA TM-107059

AIAA-95-3656

\section{SUPPLEMENTARY NOTES}

Prepared for the 1995 Space Programs and Technologies Conference sponsored by the American Institute of Aeronautics and Astronautics, Huntsville, Alabama, September 26-28, 1995. Hoai T. Ngo and Noel B. Sargent, NASA Lewis Research Center; John C. Sturman, Analex Corporation, 3001 Aerospace Parkway, Brook Park, Ohio 44142 (work funded by NASA Contract NAS3-25776). Responsible person, Hoai T. Ngo, organization code 4130, (216) 433-2533.

12a. DISTRIBUTIONAVAILABILTY STATEMENT 12b. DISTRIBUTION CODE

Unclassified -Unlimited

Subject Categories 05, 14, 18, and 33

This publication is available from the NASA Center for Aerospace Information, (301) 621-0390.

13. ABSTRACT (Maximum 200 words)

An automatic radiated susceptibility test system (ARSTS) was developed for NASA Lewis Research Center's Electromagnetic Interference laboratory. According to MSFC-SPEC 521B, any electrical or electronic equipment that will be transported by the spacelab and space shuttle must be tested for susceptibility to electromagnetic interference. This stateof-the-art automatic test system performs necessary calculations; analyzes, processes, and records a great quantity of measured data; and monitors the equipment being tested in real-time and with minimal user intervention. ARSTS reduces costly test time, increases test accuracy, and provides reliable test results.

\section{SUBJECT TERMS}

Electromagnetic interference testing

\begin{tabular}{|l|l|}
\hline \multirow{2}{*}{} & $\begin{array}{c}\text { 15. NUMBER OF PAGES } \\
5\end{array}$ \\
\cline { 2 - 3 } & $\begin{array}{c}\text { 16. PRICE CODE } \\
\text { A02 }\end{array}$ \\
\hline $\begin{array}{c}\text { 19. SECURITY CLASSIFICATION } \\
\text { OF ABSTRACT } \\
\text { Unclassified }\end{array}$ & 20. LIMITATION OF ABSTRACT \\
\hline
\end{tabular}

